Katarzyna Nabrdalik¹, Hanna Kwiendacz'1, Iga Florczyk², Maciej Gaździk ${ }^{2}$, Magdalena Domek ${ }^{2}$, Janusz Gumprecht ${ }^{1}$

${ }^{1}$ Department of Internal Medicine, Diabetology and Nephrology, Medical University of Silesia, Zabrze, Poland

2 Student Scientific Group at the Department of Internal Medicine, Diabetology and Nephrology, Medical University of Silesia, Zabrze, Poland

\title{
Knowledge about type 2 diabetes among visitors of two shopping centers in Upper Silesia, Poland: a survey research performed as a part of social action "Health under Control"
}

\section{ABSTRACT}

Introduction. Type 2 diabetes mellitus is a non-infectious epidemic of the $21^{\text {st }}$ century; therefore, it is essential to focus on prophylaxis, early detection and proper treatment in order to avoid its complications. The aim of this study was to evaluate diabetes-related knowledge among visitors of two shopping centers in Upper Silesia in Poland. The study was conducted by medical students from Medical University of Silesia in cooperation with the International Federation of Medical Students' Associations in Poland under supervision of doctors from the Department of Internal Diseases, Diabetology and Nephrology in Zabrze.

Material and methods. People were invited to fulfill a 12-item questionnaire evaluating the basic diabetesrelated knowledge (among others symptoms of hyperglycemia, risk factors, complications and treatment of diabetes mellitus). They had their weight and height

Address for correspondence:

dr n. med. Katarzyna Nabrdalik

Katedra i Klinika Chorób Wewnętrznych, Diabetologii i Nefrologii,

Śląski Uniwersytet Medyczny

Wydział Lekarski z Oddziałem Lekarsko-Dentystycznym w Zabrzu

ul. 3 Maja 13-15, 41-800 Zabrze

Phone/fax: 323704415

e-mail: knabrdalik@yahoo.com

Translation: lek. Małgorzata Kamińska

Clinical Diabetology 2018, 7, 4, 182-188

DOI: $10.5603 /$ DK.2018.0017

Received: 12.07 .2018

Accepted: 09.08.2018 measurement performed as well as glycemia measured with the use of glucometer.

Results. 401 out of 1500 invited shopping-center visitors agreed to take part in the study (27\%) and their mean score of the diabetes knowledge test was $\mathbf{5 4 . 7}$ $\pm 18.7 \%$ of the correct answers. It turned out that there is an association of knowledge about diabetes with person's age and gender - younger people and women had a better knowledge about diabetes.

Conclusions. There should be a great attention paid to different forms of education in order to improve the level of diabetes-related knowledge among the general public as a way to improve early diagnosis and a proper treatment. (Clin Diabetol 2018; 7, 4: 182-188)

Key words: knowledge, diabetes mellitus, society, education

\section{Introduction}

Type 2 diabetes (T2DM) is the first non-infectious disease that is considered an epidemic of the $21^{\text {st }}$ century. Currently one in eleven adults in the world has diabetes, which corresponds to 425 million people, of whom every second adult with diabetes is not aware of his/her illness. According to the estimations of the International Diabetes Federation (IDF), in 2045 almost 630 million people worldwide will suffer from diabetes and about $90 \%$ of them will have type 2 diabetes [1]. The estimated life expectancy of a 60-year-old diabetic patient with concomitant cardiovascular disease is 
12 years shorter compared with life expectancy for the general population [2]. In Poland, the number of diabetic patients is about 2.5 million, which is $7.8 \%$ of the country's population, and about 1.1 million people with diabetes still remain undiagnosed [1].

Diabetes is one of the ten most common causes of death in highly developed countries [1]. Studies indicate that $50 \%$ of people with diabetes die from cardiovascular diseases [3]. Therefore, of key importance is effective prevention as well as early diagnosis of type 2 diabetes in order to prevent its late complications [4].

Due to alarming data, attempts have been made to assess the awareness of diabetes in various regions of the world [1, 5-13]. The number of subjects examined in the above studies ranged from 178 people in a study conducted by Lemes dos Santos et al. in Brazil [12] to 4,000 people in a study conducted by Dorner et al. in Austria [13]. All of the conducted studies were survey based and their aim was to evaluate the knowledge about diabetes in the general population, but the questionnaires used for this purpose were different. Some of them were non-validated and created by the authors [7, $8,10,11,13]$ while others were validated questionnaires being used in previous studies $[5,6,9,12]$. Regardless of the type of the questionnaire used, the results of the conducted surveys indicate low level of knowledge of the respondents about the risk factors, symptoms, diagnosis and complications of type 2 diabetes.

Diabetes is classified as a disease of civilization; therefore, it is very important to improve public knowledge about its risk factors, symptoms and complications, especially considering that a significant percentage of people with diabetes is not aware of their illness. According to the recommendations of Diabetes Poland, people over 45 years of age should undergo screening for type 2 diabetes at least once every three years, and those with risk factors for diabetes should be examined annually regardless of age [14]. According to our knowledge, no study evaluating knowledge about type 2 diabetes among people from the general population has been published in Poland.

The aim of the study was to assess type 2 diabetesrelated knowledge among people visiting two shopping centers in Upper Silesia during a social campaign organized by medical students of the Silesian Medical University cooperating with the International Federation of Medical Students' Associations (IFMSA)-Poland.

\section{Material and methods}

Medical students, members of the Student Scientific Group at the Department of Internal Medicine, Diabetology and Nephrology in Zabrze, in cooperation with IFMSA-Poland, organized a social action entitled
"Health under Control" on 14 November 2015, the World Diabetes Day. Visitors of two shopping centers in Zabrze and Katowice were invited by students to fill in a questionnaire related to knowledge of diabetes and to undergo body mass and height measurements as well as determination of blood glucose using a glucometer. Eligible were people over 18 years of age who gave informed written consent to participate in the study. Exclusion criterion was previously diagnosed diabetes. The respondents were subjected to anthropometric measurements, i.e. body weight using the electronic medical floor scales (Charder MS 6110 class III) and growth using a portable stadiometer (Leicester Tanita HR 001), and were asked for the date of birth. Then the body mass index (BMI) of the respondent was calculated as a person's weight in kilograms, divided by height in meters squared and they were qualified to one of six BMI categories, and obese people were classified to one of three obesity classes [15].

Subsequently, a random glucose measurement was performed using an Accu Check Performa Nano blood glucometer (Roche, Switzerland).

Diabetes knowledge questionnaire used in the study was designed by medical students and was positively evaluated by two specialists in the field of diabetology and then tested on a group of 20 healthy volunteers who were members of medical students' families. The questionnaire consisted of 12 questions, including 9 single-choice questions and 3 multiplechoice questions (Table 1). The questions in the questionnaire were related to the basic knowledge about diabetes, hyperglycemia symptoms, risk factors of the development of the disease, its late complications and methods of treatment. The questionnaire was evaluated as follows: in single-choice questions, 1 point was awarded for the correct answer, 0 points for the wrong answer or "do not know" answer; in multiple-choice questions, 1 point was awarded for each correctly chosen answer, while 1 point was subtracted for an incorrectly indicated answer. The maximum score possible to obtain in the survey was 24 points. Point values were converted into a percentage of correct answers. The collected data was subjected to statistical analysis with the STATISTICA 12.5 software (StatSoft, Kraków, Poland). In order to compare near-normally distributed quantitative variables, Student's t-test was used. For variables with a non-normal distribution, the Mann-Whitney $U$ test was used to compare two independent groups, while for comparison of multiple independent samples the Kruskal-Wallis test was used. Spearman's rank correlation test was used to check the association between the variables. The statistical significance was assumed at $p<0.05$. 
Table 1. Self-constructed questionnaire with percentages of correct answers

$\%$ of responders who gave

correct answer

1 Is type 2 diabetes an infectious disease?
a) Yes
$1.79 \%$
b) No
$95.92 \%$
c) I do not know
$2.29 \%$

$2 \quad$ How does insulin work?

a) Increases blood glucose level $\quad 19.9 \%$

$\begin{array}{lr}\text { b) Lowers blood glucose level } & 62.25 \%\end{array}$

c) Does not influence blood glucose level $\quad 1.28 \%$

d) I do not know its effect on blood glucose level $\quad 8.67 \%$

$\begin{array}{ll}\text { e) I do not know what insulin is } & 7.9 \%\end{array}$

3 What are the consequences of low blood glucose?

$10.2 \%$

$\begin{array}{ll}\text { c) It causes cancer } & 1.28 \%\end{array}$

d) It is beneficial in diabetes, because it facilitates weight loss $\quad 3.83 \%$

$\begin{array}{ll}\text { e) I do not know } & 5.1 \%\end{array}$

$4 \quad$ Please indicate risk factors for diabetes?

$\begin{array}{lr}\text { a) Poor diet } & \mathbf{8 4 . 0 4 \%}\end{array}$

$\begin{array}{ll}\text { b) Smoking } & 35.68 \%\end{array}$

$\begin{array}{lr}\text { c) Low physical activity } & 28.60 \%\end{array}$

$\begin{array}{lr}\text { d) Hypertension } & 25.94 \%\end{array}$

$\begin{array}{lr}\text { e) Genetic predisposition } & 56.11 \%\end{array}$

$\begin{array}{lr}\text { f) Obesity } & 68.58 \%\end{array}$

$\begin{array}{lr}\text { g) Frequent use of antibiotics } & 15.48 \%\end{array}$

h) I do not know $\quad 6.99 \%$

$5 \quad$ What are the symptoms of diabetes?

$\begin{array}{ll}\text { a) Frequent urination } & 50.87 \%\end{array}$

$\begin{array}{ll}\text { b) Scanty urination } & 5.24 \%\end{array}$

$\begin{array}{lr}\text { c) Excessive thirst } & 68.08 \%\end{array}$

$\begin{array}{lr}\text { d) Decreased thirst } & 9.47 \%\end{array}$

$\begin{array}{ll}\text { e) Increased vitality } & 2.99 \%\end{array}$

$\begin{array}{lr}\text { f) Excessive drowsiness } & \mathbf{8 4 . 2 9 \%}\end{array}$

$\begin{array}{lr}\text { g) Increased appetite } & 23.94 \%\end{array}$

$\begin{array}{lr}\text { h) Blurred vision } & 46.13 \%\end{array}$

$\begin{array}{lr}\text { i) Cough } & 9.98 \%\end{array}$

$\begin{array}{lr}\text { j) Myalgia } & 10.72 \%\end{array}$

$\begin{array}{ll}\text { k) Unexpected weight loss } & 38.15 \%\end{array}$

$\begin{array}{ll}\text { l) I do not know } & 3.99 \%\end{array}$

6 What is the normal level of fasting blood glucose?
a) Less than $72 \mathrm{mg} / \mathrm{dL}$

a) Less than $72 \mathrm{mg} / \mathrm{dL}$

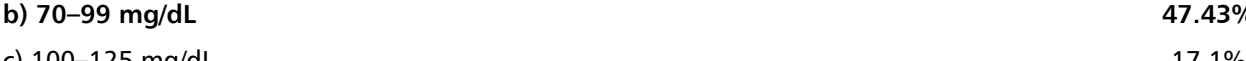

c) $100-125 \mathrm{mg} / \mathrm{dL} \quad 17.1 \%$

$\begin{array}{ll}\text { d) More than } 125 \mathrm{mg} / \mathrm{dL} & 1.28 \%\end{array}$

$\begin{array}{ll}\text { e) I do not know } & 27.04 \%\end{array}$

7 Which of the following are the complications of diabetes?
a) Kidney disease
$6.48 \%$
$\begin{array}{ll}\text { c) Coronary heart disease } & 39.90 \%\end{array}$
$\begin{array}{ll}\text { d) Damage to blood vessels } & 46.38 \%\end{array}$ 
Table 1. (cont.) Self-constructed questionnaire with percentages of correct answers

\begin{tabular}{|c|c|c|}
\hline No & Questions and answers (correct answers are indicated by bold fonts) & $\begin{array}{c}\% \text { of responders who gave } \\
\text { correct answer }\end{array}$ \\
\hline & e) Osteoporosis & $7.23 \%$ \\
\hline & f) Alzheimer disease & $7.73 \%$ \\
\hline & g) Eye damage & $69.07 \%$ \\
\hline & h) Gastric cancer & $7.23 \%$ \\
\hline & i) Diabetes foot & $67.58 \%$ \\
\hline & j) I do not know & $8.98 \%$ \\
\hline \multirow[t]{5}{*}{8} & Can complications of type 2 diabetes lead to death? & \\
\hline & a) Yes & $83.67 \%$ \\
\hline & b) No & $3.32 \%$ \\
\hline & c) Yes, but it is very rare & $10.2 \%$ \\
\hline & d) I do not know & $2.8 \%$ \\
\hline \multirow[t]{4}{*}{9} & Can diabetes type 2 be prevented? & \\
\hline & a) Yes & $94.13 \%$ \\
\hline & b) No & $1.79 \%$ \\
\hline & c) I do not know & $4.08 \%$ \\
\hline \multirow[t]{4}{*}{10} & Can diabetes be asymptomatic? & \\
\hline & a) Yes & $69.39 \%$ \\
\hline & b) No & $20.15 \%$ \\
\hline & c) I do not know & $10.46 \%$ \\
\hline \multirow[t]{6}{*}{11} & Which of the following is the basis for the treatment of type 2 diabetes? & \\
\hline & a) Dietary supplements & $24.75 \%$ \\
\hline & b) Physical activity & $0.77 \%$ \\
\hline & c) Appropriate diet & $29.83 \%$ \\
\hline & d) $b$ and $c$ & $41.33 \%$ \\
\hline & e) I do not know & $3.32 \%$ \\
\hline \multirow[t]{6}{*}{12} & Which of the following can be used for the treatment for type 2 diabetes? & \\
\hline & a) Insulin & $33.15 \%$ \\
\hline & b) Oral drugs & $1.28 \%$ \\
\hline & c) Diet & $3.06 \%$ \\
\hline & d) All above & $59.44 \%$ \\
\hline & e) I do not know & $3.07 \%$ \\
\hline
\end{tabular}

Respondents signed an informed consent form for participation in the study. According to the opinion of the Bioethics Committee of Medical University of Silesia, the study did not require the consent of this committee, because it was a social action carried out by IFMSA-Poland.

\section{Results}

1500 people visiting shopping centers in Zabrze and Katowice were invited to participate in the study, of which 401 (27\%) agreed to be interviewed and examined, including $52.2 \%$ women $(n=209)$. Mean $( \pm S D)$ age of the respondents was $45.26 \pm 17.21$ years. Demographic and anthropometric data are presented in Table 2. Table 3 presents the distribution of obesity in the population of the study. The mean ( \pm SD) score of the diabetes knowledge test was $54.7 \pm 18.7 \%$ (minimum score 12.5\%; maximum score $95.8 \%$ ). The distribution of test results in the study population by age and gender is presented in Table 4. Multivariate analysis of variance showed a significant relationship between the score obtained in the knowledge test and the age and gender of the respondent. Younger subjects and women had better knowledge about diabetes ( $p=0.008$ and $p=0.019$, respectively). $84 \%$ of respondents indicated that poor diet is a risk factor for the development of type 2 diabetes, while only $25.9 \%$ chose hypertension in this question. Excessive drowsiness was most often indicated (84.3\%) as the symptom of diabetes, and unexpected weight loss 
Table 2. Demographic and anthropometric data

\begin{tabular}{lccc}
\hline & All respondents & Men & $\begin{array}{c}\text { Women } \\
(\mathbf{n}=\mathbf{2 0 9})\end{array}$ \\
\hline Age (years) M \pm SD & $45.29 \pm 17.19$ & $44.72 \pm 17.59$ & $45.76 \pm 16.94$ \\
Body weight [kg] M \pm SD & $73.14 \pm 15.22$ & $80.66 \pm 13.67^{*}$ & $66.66 \pm 12.45^{*}$ \\
Height [m] M \pm SD & $1.69 \pm 0.09$ & $1.74 \pm 0.074^{*}$ & $1.64 \pm 0.06^{*}$ \\
BMI $\left[\mathrm{kg} / \mathrm{m}^{2}\right] \mathrm{M} \pm$ SD & $25.64 \pm 4.79$ & $26.54 \pm 4.18^{*}$ & $24.95 \pm 4.88^{*}$ \\
Suspicion of type 2 diabetes based on a blood glucose measure- & $1.25 \%(\mathrm{n}=5)$ & $0.75 \%(\mathrm{n}=3)$ & $0.5 \%(\mathrm{n}=2)$ \\
ment performed during the social action & & & \\
\hline
\end{tabular}

*Statistical difference between women and men, $\mathrm{p}<0.05$

$\mathrm{M}$ - mean; SD — standard deviation; BMI — body mass index

Table 3. Distribution of obesity (according to WHO classification) in studied population [15]

\begin{tabular}{lccc}
\hline BMI class & BMI value & Number of respondents & Per cent of respondents \\
\hline 1 (underweight) & $<18.5$ & 14 & $3.48 \%$ \\
2 (normal weight) & $18.5-24.9$ & 180 & $44.89 \%$ \\
3 (overweight) & $25-29.9$ & 142 & $35.41 \%$ \\
4 (class I obesity) & $30-34.9$ & 47 & $11.72 \%$ \\
5 (class II obesity) & $35-39.9$ & 13 & $3.24 \%$ \\
6 (class III obesity) & $\geq 40$ & 3 & $0.75 \%$ \\
\hline
\end{tabular}

$\mathrm{BMI}$ - body mass index

Table 4. Distribution of the results of the survey in studied population by age and gender

\begin{tabular}{lcc}
\hline Variable & Survey result & $\mathbf{p}$ (U Mann-Whitney test) \\
\hline Age & & \\
$<45.26$ years & $57.1 \% \pm 19.2$ & 0.008 \\
$\geq 45.26$ years & $52.1 \% \pm 17.9$ & \\
Gender & \\
M & $52.4 \% \pm 18.9$ & 0.019 \\
K & $56.7 \% \pm 18.4$ & \\
\hline
\end{tabular}

was the least often one (38.2\%). Among incorrect answers also, some respondents (23.9\%) considered "increased appetite" as a symptom of diabetes. As much as $69.1 \%$ respondents indicated eye damage as a complication of diabetes, and only $39.9 \%$ chose coronary heart disease. Detailed distribution of participants' answers to test questions is shown in Table 1 . In five people ( $0.9 \%$ of the respondents) the random glucose concentration was above $300 \mathrm{mg} / \mathrm{dL}$; therefore, they were advice that they should have their venous blood glucose measured in the fasting state and urgently consult the obtained laboratory blood test result with a doctor.

\section{Discussion}

Less than $30 \%$ of invited people agreed to participate in the study, and the mean percentage of correct answers from the questionnaire was $54.7 \%$. Considering increasing incidence of type 2 diabetes, such a low proportion of people interested in this health problem and a considerably low score in the test of knowledge about type 2 diabetes is an important factor indicating the urgent need for educating people from the general population about diabetes. Among the survey based studies assessing diabetes related knowledge of people from general population only in a few of them the percentage of people who agreed to participate in the study was reported and it ranged from $42 \%$ in the study by Dorner et al. [13] to $91 \%$ in the study by Lorga et al. [8]. In five people ( $0.9 \%$ of respondents) who participated in our study, diabetes was suspected and further diagnostics for diabetes recommended, which confirms a significant number of patients with undiagnosed diabetes [16]. To our knowledge, this is the first study of this type in Poland assessing knowledge about type 2 diabetes. Due to the differences in the questionnaires used in previous studies, it is not possible to directly compare obtained results reflecting the knowledge of the surveyed people. 
The results of our research indicate that women and younger people had the best knowledge about diabetes. These groups of respondents knew more about diabetes control and how to recognize the symptoms of hyper- and hypoglycemia. Women proved to have better knowledge about diabetes also in a study conducted by Demaio et al. who used a self-constructed questionnaire and in a study by Lemes dos Santos et al. who used the Portuguese version of a validated questionnaire from the Starr County Diabetes Education Study [10, 12]. According to a study conducted in 2010 by Cohen and Stussmann, greater awareness of diabetes among women may be caused by the fact that they are more interested than men in websites providing health-related information, where they can expand their basic knowledge on various diseases, and more often join online chat groups to discuss health topics [17]. Respondents older than the average age of study participants, which was 45 years, achieved a significantly lower score compared with those below the average age $(52.1 \% \pm 17.9$ and $57.1 \% \pm 19.2$ respectively; $p=0.008)$. Considering the above observation and the fact that the risk of developing type 2 diabetes increases with age, special attention should be paid to the education of people in this age group. Greater awareness of younger respondents may be associated with better access to social media and the Internet, which nowadays may be an invaluable source of knowledge, as well as with greater susceptibility to education.

About $50 \%$ of respondents were overweight or obese; however, their test score did not differ significantly from that of the respondents with normal body weight. The results of the study also showed that the respondents knew little about the risk factors, symptoms and complications of diabetes. Less than one-third of the respondents were aware that low physical activity is a factors that can contribute to the development of diabetes. The results obtained in our study are in line with those from the study conducted by Binh et al. who assessed the awareness of diabetes among 2,580 healthy inhabitants of Vietnam [9]. In this survey study, only $30.1 \%$ of respondents correctly indicated obesity as a risk factor for diabetes, and as few as $2.6 \%$ were able to correctly indicate sedentary lifestyle as a factor playing a role in the development of the disease [9].

In our study, only $38.15 \%$ of respondents correctly indicated sudden weight loss and $46.13 \%$ worsening of vision as symptoms of diabetes. Only $39.90 \%$ of the respondents knew that coronary heart disease may be a complication of diabetes, although it is the main cause of death in people with diabetes. In our study, $47.43 \%$ of the respondents were able to indicate normal level of fasting blood glucose. This suggest that people living in Upper Silesia had better knowledge about diabetes than the population of a study performed by Lorga et al. who surveyed 299 members of the Karen tribe (residents of Thailand) using self-constructed questionnaire and reported that less than $30 \%$ of respondents were able to correctly indicate normal blood glucose level [8].

\section{Conclusions}

As mentioned in the introduction, in accordance with the recommendations of the Diabetes Poland, every person over 45 years of age should undergo screening for type 2 diabetes at least once every three years, and in those with risk factors for diabetes such examination should be performed annually regardless of age [14]. It should be noted, that our study showed that people over 45 years of age were characterized by the lowest score in the test of knowledge about diabetes and, what is more, in nearly $1 \%$ of respondents random glycemia was $>300 \mathrm{mg} / \mathrm{dL}$ and overt diabetes was suspected. It is also alarming that the respondents did not know that a sedentary lifestyle with low physical activity are risk factors for type 2 diabetes. In conclusion, it is necessary to emphasize the need for education of people from general population regarding type 2 diabetes, especially its risk factors and the role of lifestyle modification and body weight control. Improving public knowledge about diabetes could contribute to prevention or early diagnosis of the disease and its proper treatment in order to reduce the risk of chronic complications of diabetes.

\section{Conflict of interest}

None declared.

\section{REFERENCES}

1. International Diabetes Federation. IDF Diabetes Atlas, 8th edn. Brussels, Belgium: International Diabetes Federation, 2017. http:// www.diabetesatlas.org

2. Seshasai SRK, Kaptoge S, Thompson A, et al. Emerging Risk Factors Collaboration. Diabetes mellitus, fasting glucose, and risk of cause-specific death. N Engl J Med. 2011; 364(9): 829-841, doi: 10.1056/NEJMoa1008862, indexed in Pubmed: 21366474.

3. Pildava S, Strēle I, Briǵis G. The mortality of patients with diabetes mellitus in Latvia 2000-2012. Medicina (Kaunas). 2014; 50(2): 130-136, doi: 10.1016/j.medici.2014.06.005, indexed in Pubmed: 25172608.

4. Murata GH, Shah JH, Adam KD, et al. Factors affecting diabetes knowledge in type 2 diabetic veterans. Diabetologia. 2003; 46(8): 1170-1178, doi: 10.1007/s00125-003-1161-1, indexed in Pubmed: 12856126.

5. Islam FM, Chakrabarti R, Dirani M, et al. Knowledge, attitudes and practice of diabetes in rural Bangladesh: the Bangladesh Population based Diabetes and Eye Study (BPDES). PLoS One. 2014; 9(10): e110368, doi: 10.1371/journal.pone.0110368, indexed in Pubmed: 25313643. 
6. Ahmad B, Khalid BAK, Quek KF, et al. Knowledge of diabetes and lifestyle behaviour amongst indigenous population in Peninsular Malaysia, Med J Malaysia 2013; 68(4), 309-314. PMID: 24145258.

7. Pongmesa T, Li SC, Wee HL. A survey of knowledge on diabetes in the central region of Thailand. Value Health. 2009; 12 Suppl 3: S110-S113, doi: 10.1111/j.1524-4733.2009.00641.x, indexed in Pubmed: 20586971.

8. Lorga T, Srithong K, Manokulanan P, et al. Public knowledge of diabetes in Karen Ethnic rural residents: a community-based questionnaires study in the far north-west of Thailand. Int J Gen Med. 2012; 5: 799-804, doi: 10.2147/IJGM.S33177, indexed in Pubmed: 23055769.

9. Binh $\mathrm{T}$, Phuong $\mathrm{P}$, Nhung B. Knowledge and associated factors towards type 2 diabetes among a rural population in the Red River Delta region, Vietnam. Rural Remote Health 2015; 15: 3275. http://www.rrh.org.au/journal/article/3275.

10. Demaio AR, Dugee $O$, de Courten $M$, et al. Exploring knowledge, attitudes, and practices related to alcohol in Mongolia: a national population-based survey. BMC Public Health. 2013; 13: 178, doi: 10.1186/1471-2458-13-178, indexed in Pubmed: 23445523.

11. Mukeshimana MM, Nkosi ZZ. Communities' knowledge and perceptions of type two diabetes mellitus in Rwanda: a questionnaire survey. J Clin Nurs. 2014; 23(3-4): 541-549, doi: 10.1111/ /jocn.12199, indexed in Pubmed: 23789978.
12. Lemes Dos Santos PF, Dos Santos PR, Ferrari GS, et al. Knowledge of diabetes mellitus: does gender make a difference? Osong Public Health Res Perspect. 2014; 5(4): 199-203, doi: 10.1016/j. phrp.2014.06.004, indexed in Pubmed: 25379370.

13. Dorner TE, Lackinger $C$, Schindler $K$, et al. Health information regarding diabetes mellitus reduces misconceptions and underestimation of consequences in the general population. Public Health Nutr. 2013; 16(11): 2032-2039, doi: 10.1017/ /S1368980012003886, indexed in Pubmed: 22931860.

14. Guidelines on the management of diabetic patients. A position of Diabetes Poland. Clinical Diabetology. 2018; 7(1): 1-90, doi: 10.5603/dk.2018.0001.

15. Obesity: Preventing and managing the global epidemic. Consultation, W. H. O. 2000. http://www.who.int/nutrition/publications/ /obesity/WHO_TRS_894/en/.

16. Drągowski P, Czyżewska U, Cekała E et al. Cukrzyca jako problem społeczny i ekonomiczny. Polski Przegląd Nauk o Zdrowiu. 2014; 39 (2): 163-166. http://www.przeglad.amp.edu.pl/issue. php?id=9.

17. Cohen RA, Stussman B. Health information technology use among men and women aged 18-64: Early release of estimates from the National Health Interview Survey, January-June 2009. Health E-Stats. National Center for Health Statistics. February 2005. https://www.cdc.gov/.../hestat/healthinfo2009/healthinfo 2009.pdf. 